\title{
Local Random Pattern Flap Coverage for Implant Exposure following Open Reduction Internal Fixation via Extensile Lateral Approach to the Calcaneus
}

\author{
Yingjie Liu, Peihua Cai, Liang Cheng ${ }^{*}$ and Yanfeng Li
}

\begin{abstract}
Background: Skin necrosis and implant exposure most often appear at the corner of Extensile Lateral Approach for open reduction and internal fixation (ORIF) for displaced intra-articular fracture of the calcaneus. Flap transfer is often used for coverage of this implant exposure. We introduced a new simple local random pattern flap to cover the implant exposure.

Methods: From March 2017 to March 2020, 12 patients with implant exposure after ORIF for displaced intraarticular fracture of the calcaneus were treated with this procedure. The sizes of the defects ranged from $2 \times 2 \mathrm{~cm}^{2}$ to $5 \times 2 \mathrm{~cm}^{2}$. A local random pattern flap was designed according to the defect size. The lower edge of the flap was along with the wound upper edge and extended distally. The upper horizontal incision of the flap was made at the lateral malleolus level with a length of 5-7 cm depending on the wound defect. Then the random pattern flap was elevated and transferred to cover the defect area.

Results: The mean follow-up duration was 6.3 months (ranging 4-13 months). All 12 flaps were uneventfully healed and all patients were able to wear shoes, and no debulking procedures were required.

Conclusion: The local random pattern flap could be a choice for surgeons when implant exposure at the corner of Extensile Lateral Approach to the Calcaneus occurs.
\end{abstract}

Keywords: Lateral approach calcaneus, Random pattern flap, Implant exposure

\section{Introduction}

Calcaneal fracture comprises $1-2 \%$ of all fractures which is the most frequently fractured of all the tarsal bones [1]. 71\% of calcaneal fractures are intra-articular calcaneal fractures, which are the most challenging types for treatment [2]. The management of Displaced intraarticular calcaneal fractures can be divided into four categories: non-operative management; open reduction and internal fixation (ORIF); minimally invasive reduction

\footnotetext{
*Correspondence: chan_liang@alumni.sjtu.edu.cn

Department of Orthopedics, Shanghai Jiao Tong University Affiliated Sixth People's Hospital, 600 Yishan road, Shanghai 200233, China
}

and fixation; primary ORIF and subtalar arthrodesis [2]. Open reduction and internal fixation (ORIF) for displaced intra-articular fracture of the calcaneus has been widely advocated by most experts, as it generally provides good to excellent functional outcomes and the ability to anatomically restore the subtalar joint $[3,4]$. Several open Operative techniques have been described in the past, of which the extended lateral approach has been applied most frequently [5-8]. The rate of wound complications after ORIF of closed calcaneal fractures via the extensile lateral approach has ranged from 0 to $27 \%[5,9]$. The corner of Extensile Lateral Approach to

(C) The Author(s). 2021 Open Access This article is licensed under a Creative Commons Attribution 4.0 International License, which permits use, sharing, adaptation, distribution and reproduction in any medium or format, as long as you give appropriate credit to the original author(s) and the source, provide a link to the Creative Commons licence, and indicate if changes were made. The images or other third party material in this article are included in the article's Creative Commons licence, unless indicated otherwise in a credit line to the material. If material is not included in the article's Creative Commons licence and your intended use is not permitted by statutory regulation or exceeds the permitted use, you will need to obtain permission directly from the copyright holder. To view a copy of this licence, visit http://creativecommons.org/licenses/by/4.0/. The Creative Commons Public Domain Dedication waiver (http://creativecommons.org/publicdomain/zero/1.0/) applies to the data made available in this article, unless otherwise stated in a credit line to the data. 
the Calcaneus is the most likely site of wound healing complications, with skin necrosis. Skin necrosis and implant exposure most often appear in this area.

Flap transfer is often used for coverage of such implant exposure. Mueller et al reported that they used the musculocutaneous sural artery flap for coverage of implant exposure after calcaneal fracture [10]. However, there is often morbidity at the donor site and shoe-fitting problems because of a bulky contour. A free flap is also used to cover calcaneal soft-tissue defects [11], but the procedure is timeconsuming and technically demanding. In this study, we used a local random skin flap for soft tissue coverage of implant exposure after calcaneal fracture procedures.

\section{Materials and Methods}

A retrospective review was performed of patients with implant exposure after calcaneal fracture procedures from March 2017 to March 2020. This study was approved by the Institutional Review Board of Shanghai Jiao Tong University Affiliated Sixth People's Hospital. 12 patients out of all 22 patients with implant exposure at the corner of the Extensile Lateral Approach to the Calcaneus were included in this study. The exclusion criteria: the positive culture result of wound specimen collection before operation was excluded.

Seven of the patients were men and five were women with a mean age of 44 years (range, $32-59$ years). The sizes of the defects ranged from $2 \times 2 \mathrm{~cm}^{2}$ to $5 \times 2 \mathrm{~cm}^{2}$. The details of the included cases are listed in Table 1 . Six of the patients were smokers and they were asked to stop smoking before the operation. Blood glucose levels were kept under $10.0 \mathrm{mmol} / \mathrm{L}$ in the four diabetic patients by injecting insulin before the operation.

\section{Operative Technique}

A debridement and a negative-pressure dressing were applied for 3-5 days. Then the wound specimens were collected for microbial cultures and the wounds were covered by a negative-pressure dressing. When the cultures of wound specimen collection were negative, the local random flap was used to cover the wounds (Figs. 1 and 2).

Patients were placed in a lateral position for the local random pattern flap procedure. A local random pattern flap was designed according to the defect size. The lower edge of the flap was along with the wound upper edge and extended distally. The upper horizontal incision of the flap was made at the lateral malleolus level with a length of 5-7 cm depending on the wound defect (Fig. 3). The lesser saphenous vein and the sural nerve were dissected and protected carefully. Then the random pattern flap was elevated and transferred to cover the defect area. The donor site was covered by a split-thickness skin graft (Figs. 4 and 5). The mean operative time was 40-60 min.

\section{Postoperative Treatment}

The patients remained in bed for 2 weeks, avoiding any pressure on the flap by suspending the leg on an external device. Low molecular weight dextran was given to improve the micro-circulation, and antibiotics were administered for $48 \mathrm{~h}$ to prevented infection. The six smoking patients were asked to stop smoking. Blood glucose levels were maintained below $10.0 \mathrm{mmol} / \mathrm{L}$ in the four diabetic patients.

\section{Results}

The mean follow-up duration was 6.3 months (range 413 months). All the patients were satisfied with the functional and aesthetic results (Table 1). During the followup period, all patients were able to wear shoes, and no debulking procedures were required (Fig. 6). The ankle range of motion was preserved in nine patients, and was

Table 1 Patient demographics and outcomes

\begin{tabular}{lllllllll}
\hline Patient & Age (years) & Sex & Defect size $\left.\mathbf{( c m}^{\mathbf{2}}\right)$ & NPD & Smoker & Diabetes & Flap survival & ROM \\
\hline 1 & 32 & M & $3 \times 2$ & Yes & Yes & No & Complete & Fully \\
2 & 37 & F & $2 \times 2$ & No & No & No & Complete & Fully \\
3 & 43 & M & $2 \times 2$ & No & Yes & Yes & Complete & Fully \\
4 & 50 & M & $5 \times 2$ & Yes & No & No & Complete & Slightly reduced \\
5 & 51 & F & $4 \times 2$ & Yes & No & Yes & Complete & Slightly reduced \\
6 & 59 & M & $3 \times 2$ & Yes & Yes & No & Complete & Fully \\
7 & 41 & F & $2 \times 2$ & No & No & No & Complete & Fully \\
8 & 43 & M & $4 \times 2$ & Yes & Yes & Yes & Complete & Slightly reduced \\
9 & 35 & M & $2 \times 2$ & No & Yes & No & Complete & Fully \\
10 & 54 & F & $3 \times 2$ & Yes & No & Yes & Complete & Fully \\
11 & 49 & F & $3 \times 2$ & Yes & No & No & Complete & Fully \\
12 & 33 & M & $2 \times 2$ & No & Yes & No & Complete & Fully \\
\hline
\end{tabular}




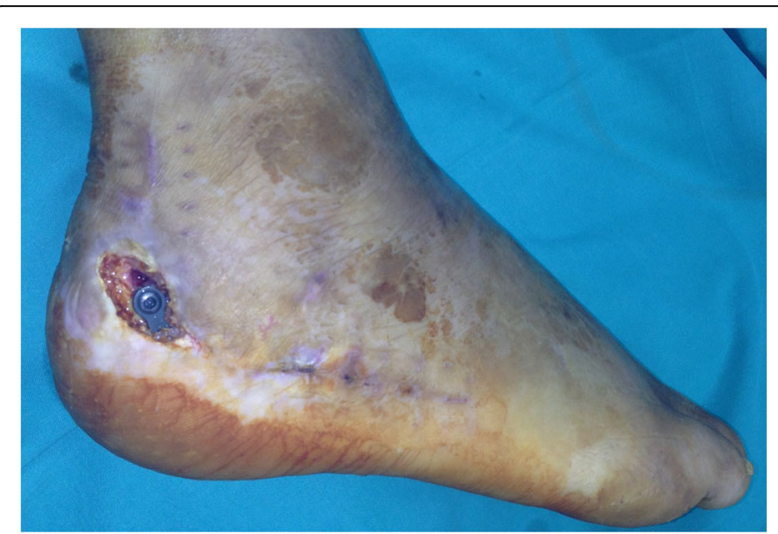

Fig. 1 Skin necrosis after ORIF for displaced intra-articular fracture of the calcaneus. There is a skin defect over the hardware

slightly reduced in three patients. However, all patients were able to walk without walking aids.

\section{Discussion}

The extended lateral approach is widely applied for intra-articular calcaneal fracture ORIF and offers advantages of achieving adequate fracture reduction with the risk of wound-healing complications and infection [12]. An L-shaped lateral incision is made to expose the calcaneus, but the corner of the incision is the most likely site of wound healing complications, such as necrosis. Skin necrosis, wound dehiscence, and plate exposure most often appear in this area, because there is less subcutaneous tissue under the lateral calcaneal flap. Blood flow to the lateral calcaneal flap is primarily supplied by the lateral calcaneal artery (LCA), and complications in wound healing, such as ischemia of the lateral calcaneal flap, can arise from damage to the LCA. Borrelli et al. concluded that, based on the position of the LCA, it is vulnerable to injury caused by the vertical incision in the lateral approach [13].

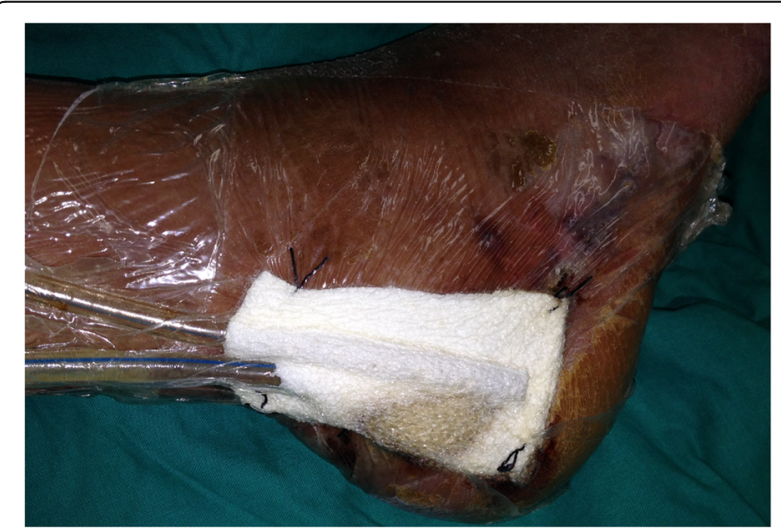

Fig. 2 After wound debridement, a negative-pressure dressing was applied to wound

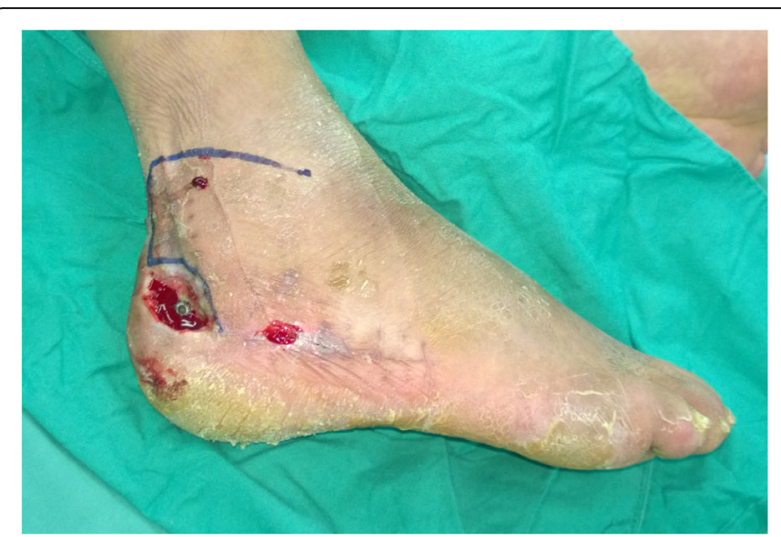

Fig. 3 The design of the local random pattern flap

Smoking has a detrimental effect on the healing of wounds. Smoking causes blood vessels to contract, thus reducing blood supply to the extremities, with decreases in the contractility of vessels, blood flow rate, and efficiency of oxygen transportation. These negative effects are reversible [14]. The literature generally confirms that nicotine abstinence for $4-8$ weeks preoperatively is advantageous and post-operative complications may be reduced if patients refrain from smoking for 10 days after surgery $[15,16]$. In our study, the six smoking patients were asked to stop smoking before the operation and to abstain for another 2 weeks postoperatively. The flaps in all six patients healed uneventfully.

Diabetes was considered as a significant independent risk factor for wound complications [17]. Diabetes can impede wound healing and predispose patients to infection through ischemia secondary to microvascular abnormality. In this study wound complication after ORIF occurred in all four diabetic patients. During the flap operation period, the blood glucose levels were maintained below $10.0 \mathrm{mmol} / \mathrm{L}$ in all four diabetic patients by insulin injection. Finally, the flap survived.

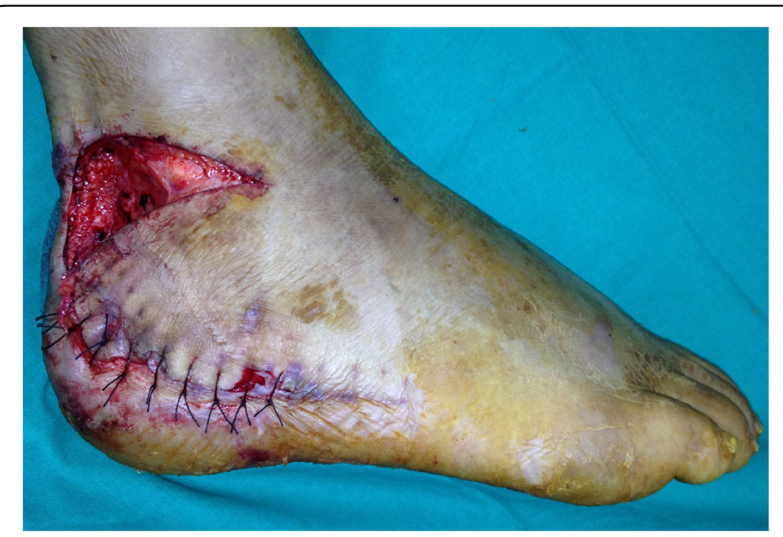

Fig. 4 A local random pattern flap was transferred to cover the skin defect 


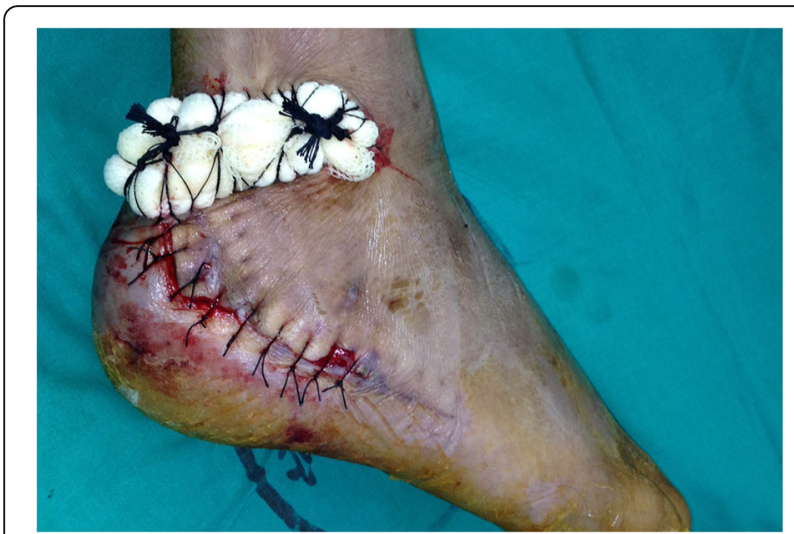

Fig. 5 The donor site was covered by split-thickness skin graft

When skin flap necrosis occurs at the corner of the Extensile Lateral Approach, local wound care, debridement, changing dressings, antibiotics and skin flap transplantation should be attempted, in that order, with a favourable outcome being largely dependent on early diagnosis and treatment [18]. Herscovici et al. reported that debridement of all necrotic tissue and changing dressings once a day using thick povidone iodine gauze often resulted in a good outcome [19]. However, if the necrotic area results in implant exposure, skin flap transplantation might be needed. A reversed sural nerve flap is most frequently used because of its rich blood supply and the simplicity of the operation [20]. The most common complication encountered with the reversed sural type of flap is venous congestion which may result in partial- or full- thickness flap necrosis [21]. Transfer of a free flap has also been reported to cover a defect in this area [11]. This technique requires specialized microsurgical training and is best performed in patients who are able to withstand prolonged general anesthesia [22]. There is also morbidity at the donor site and later shoe-

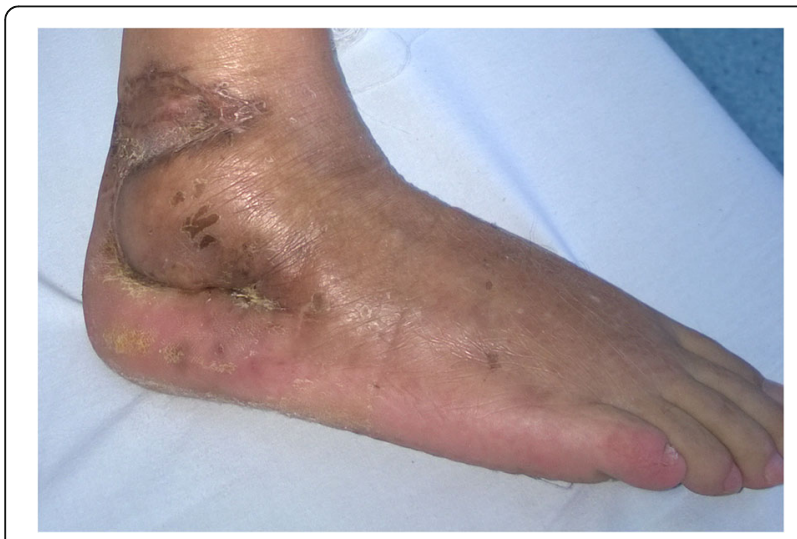

Fig. 6 Flap healed uneventfully with good functional and aesthetic result fitting problems because of a bulky contour. The abductor digiti minimi (ADM) flap can be used for small defects at the corner of the Extensile Lateral Approach. CL Wang et al reported that they used the abductor digiti minimi muscle flap as a muscular plug between the wound and the plate after ORIF of calcaneus fractures [23] . However, loss of the ADM muscle may result in lack of plantar lateral padding, which may result in discomfort. In this study, we reported a local random pattern flap for coverage of the skin necrotic area with implant exposure. Local random pattern flaps are flaps whose success depends on a length-to-width ratio (1.5:1) with no specific blood flow at their base. Attinger et al. used a local muscle flap for the treatment of hardware exposure [24]. In our cases, we used a local random pattern flap to cover the hardware exposure. The benefits of this flap include a similar tissue composite of the hardware exposure area, no specialized microsurgical training, and easy for surgeons to operate.

However, our technique has a limitation. Before applying the local random flap for hardware exposure, we needed to collect some wound specimen for culturing to indentify pathogens. If the result was positive which implied that there was a deep infection at the surgery site, the local random flap was not recommended. Thus, in this study, the wound specimen was collected and cultured to indentify pathogens before operations. The local random flap was applied to the patients with negative results.

\section{Conclusion}

Our study is the first report of the simple flap, a local random pattern flap, for the coverage of implant exposure after ORIF for calcaneal fractures. All 12 flaps were uneventfully healed. The random pattern flap probably survived through perfusion from a perforator from the anastomotic arcade around the ankle. However, the reliability of the local random pattern flap needs to be further evaluated with a larger number of patients. The technique under discussion will need a larger and preferably multicentric study to finally assess the reliability of the technique. Nevertheless, the flap procedure is easy to perform and needs no microsurgery skills. It could be an option for surgeons when implant exposure occurs at the corner of Extensile Lateral Approach.

\section{Acknowledgements \\ We would like to thank all the staff in the Department of Orthopedic Surgery, Shanghai Jiao Tong University Affiliated Sixth People's Hospital for their help on this study.}

\section{Authors' contributions}

Peihua Cai and Liang Cheng designed the study. Liang Cheng wrote the first draft of the manuscript. Liang Cheng, Yingjie Liu and Peihua Cai performed the procedure. Yanfeng Li collected the data. The authors read and approved the final mauscript. 
Funding

No.

\section{Availability of Data and Materials}

The datasets generated during and analyzed during the current study are not publicly available due to the privacy policy but are available from the corresponding author on reasonable request.

\section{Declaration}

\section{Ethics Approval and Consent to Participate}

This study was approved by the Institutional Review Board of Shanghai Jiao Tong University Affiliated Sixth People's Hospital. All methods were carried out in accordance with relevant guidelines and regulations. Written informed consent was obtained from all patients enrolled in the investigation.

\section{Consent for Publication}

All the patients in this study have given their informed consent for the article to be published.

\section{Competing Interests}

The authors declare that they have no competing interests.

Received: 8 January 2021 Accepted: 11 May 2021

Published online: 21 June 2021

\section{References}

1. Vosoughi AR, Borazjani R, Ghasemi N, Fathi S, Mashhadiagha A, Hoveidaei $\mathrm{AH}$. Different types and epidemiological patterns of calcaneal fractures based on reviewing $C T$ images of 957 fractures. Foot Ankle Surg. 2021 S1268-7731(21):00028-X. https://doi.org/10.1016/j.fas.2021.02.002. Epub ahead of print.

2. Sharr PJ, Mangupli MM, Winson IG, Buckley RE. Current management options for displaced intra-articular calcaneal fractures: non-operative, ORIF, minimally invasive reduction and fixation or primary ORIF and subtalar arthrodesis. A contemporary review. Foot Ankle Surg. 2016;22(1):1-8.

3. Sanders R. Displaced intra-articular fractures of the calcaneus. J Bone Joint Surg Am. 2000;82(2):225-50.

4. Veltman ES, Doornberg JN, Stufkens SA, Luitse JS, van den Bekerom MP Long-term outcomes of 1,730 calcaneal fractures: systematic review of the literature. J Foot Ankle Surg. 2013;52(4):486-90

5. Benirschke SK, Sangeorzan BJ. Extensive intraarticular fractures of the foot. Surgical management of calcaneal fractures. Clin Orthop Relat Res. 1993;292: 128-34

6. Buckley R, Tough S, McCormack R, Pate G, Leighton R, Petrie D, et al. Operative compared with nonoperative treatment of displaced intraarticular calcaneal fractures: a prospective, randomized, controlled multicenter trial. J Bone Joint Surg Am. 2002;84-A(10):1733-44.

7. Sanders R, Fortin P, DiPasquale T, Walling A. Operative treatment in 120 displaced intraarticular calcaneal fractures. Results using a prognostic computed tomography scan classification. Clin Orthop Relat Res. 1993;290: 87-95.

8. Zeman P, Zeman J, Matejka J, Koudela K. Long-term results of calcaneal fracture treatment by open reduction and internal fixation using a calcaneal locking compression plate from an extended lateral approach. Acta Chir Orthop Traumatol Cechoslov. 2008;75(6):457-64.

9. Stephenson JR. Surgical treatment of displaced intraarticular fractures of the calcaneus. A combined lateral and medial approach. Clin Orthop Relat Res. 1993;290:68-75.

10. Mueller JE, Ilchmann T, Lowatscheff $\mathrm{T}$. The musculocutaneous sural artery flap for soft-tissue coverage after calcaneal fracture. Arch Orthop Trauma Surg. 2001;121(6):350-2.

11. Kim SW, Youn DH, Hwang KT, Sung $H_{\text {, }}$ Kim JT, Kim YH. Reconstruction of the lateral malleolus and calcaneus region using free thoracodorsal artery perforator flaps. Microsurgery. 2016;36(3):198-205.

12. Stapleton JJ, Zgonis T. Surgical treatment of intra-articular calcaneal fractures. Clin Podiatr Med Surg. 2014;31(4):539-46.

13. Borrelli J Jr, Lashgari C. Vascularity of the lateral calcaneal flap: a cadaveric injection study. J Orthop Trauma. 1999;13(2):73-7.
14. Thomsen T, Tonnesen H, Moller AM. Effect of preoperative smoking cessation interventions on postoperative complications and smoking cessation. Br J Surg. 2009;96(5):451-61.

15. Moller AM, Villebro N, Pedersen T, Tonnesen H. Effect of preoperative smoking intervention on postoperative complications: a randomised clinical trial. Lancet. 2002;359(9301):114-7.

16. Thomsen T, Villebro N, Moller AM. Interventions for preoperative smoking cessation. Cochrane Database Syst Rev. 2014;3:CD002294.

17. Ding L, He Z, Xiao H, Chai L, Xue F. Risk factors for postoperative wound complications of calcaneal fractures following plate fixation. Foot Ankle Int. 2013:34(9):1238-44.

18. Folk JW, Starr AJ, Early JS. Early wound complications of operative treatment of calcaneus fractures: analysis of 190 fractures. J Orthop Trauma. 1999;13(5): 369-72.

19. Herscovici D Jr, Widmaier J, Scaduto JM, Sanders RW, Walling A. Operative treatment of calcaneal fractures in elderly patients. J Bone Joint Surg Am. 2005;87(6):1260-4.

20. Gupta A, Ghalambor N, Nihal A, Trepman E. The modified Palmer lateral approach for calcaneal fractures: wound healing and postoperative computed tomographic evaluation of fracture reduction. Foot Ankle Int. 2003;24(10):744-53.

21. Parrett BM, Pribaz JJ, Matros E, Przylecki W, Sampson CE, Orgill DP. Risk analysis for the reverse sural fasciocutaneous flap in distal leg reconstruction. Plast Reconstr Surg. 2009;123(5):1499-504.

22. Bibbo C, Siddiqui N, Fink J, Powers J, Ehrlich DA, Kovach SJ. Wound coverage options for soft tissue defects following calcaneal fracture management (operative/surgical). Clin Podiatr Med Surg. 2019;36(2):323-37.

23. Wang CL, Huang SF, Sun XS, Zhu T, Lin C, Li Q. Abductor digiti minimi muscle flap transfer to prevent wound healing complications after ORIF of calcaneal fractures. Int J Clin Exp Med. 2015;8(8):13001-6.

24. Attinger $C$, Cooper $P$. Soft tissue reconstruction for calcaneal fractures or osteomyelitis. Orthop Clin North Am. 2001;32(1):135-70.

\section{Publisher's Note}

Springer Nature remains neutral with regard to jurisdictional claims in published maps and institutional affiliations.

Ready to submit your research? Choose BMC and benefit from:

- fast, convenient online submission

- thorough peer review by experienced researchers in your field

- rapid publication on acceptance

- support for research data, including large and complex data types

- gold Open Access which fosters wider collaboration and increased citations

- maximum visibility for your research: over $100 \mathrm{M}$ website views per year

At BMC, research is always in progress.

Learn more biomedcentral.com/submissions 